\title{
ARTICLE
}

\section{Lead-Free Organic-Inorganic Tin Halide Perovskites for Photovoltaic Applications}

Cite this: DOI: 10.1039/xoxxooooox

Received ooth January 2012, Accepted ooth January 2012

DOI: $10.1039 /$ xoxxooooox

www.rsc.org/

\author{
Nakita K. Noel, ${ }^{a}$ Samuel D. Stranks, ${ }^{a}$ Antonio Abate, ${ }^{a}$ Christian Wehrenfennig, ${ }^{a}$ \\ Simone Guarnera, ${ }^{b, c}$ Amir Abbas Haghighirad, ${ }^{a}$ Aditya Sadhanala, ${ }^{d}$ Giles E. \\ Eperon, ${ }^{a}$ Michael B. Johnston, ${ }^{a}$ Anna Maria Petrozza, ${ }^{b}$ Laura M. Herz, ${ }^{a}$ Henry J. \\ Snaith $^{a^{*}}$
}

\begin{abstract}
Already exhibiting solar to electrical power conversion efficiencies of over $16 \%$, organicinorganic lead halide perovskite solar cells are one of the most promising emerging contenders in the drive to provide a cheap and clean source of energy. One concern however, is the potential toxicology issue of lead, a key component in the archetypical material. The most likely substitute is tin, which like lead, is also a group 14 metal. While organic-inorganic tin halide perovskites have shown good semiconducting behaviour, the instability of tin in its 2+ oxidation state has thus far proved to be an overwhelming challenge. Here we report the first completely lead-free, $\mathrm{CH}_{3} \mathrm{NH}_{3} \mathrm{SnI}_{3}$ perovskite solar cell processed on a mesoporous $\mathrm{TiO}_{2}$ scaffold, reaching efficiencies of over $6 \%$ under 1 sun illumination. Remarkably, we achieve open circuit voltages over $0.88 \mathrm{~V}$ from a material which has a $1.23 \mathrm{eV}$ band gap.
\end{abstract}

\section{Introduction}

With increasing industrialisation and a growing population, the energy demands of today's society will continue to grow. Faced with a dwindling supply of fossil fuels and adverse climate change, the search for a viable source of renewable energy is ongoing. Of all available forms of renewable energy, solar energy is one of the most promising. At present, the photovoltaic market is dominated by solar cells made of crystalline silicon however, even in light of the major decrease in the price of crystalline silicon, the high production and installation costs lead to long payback times in most regions, decreasing the economic feasibility of widespread use. ${ }^{1}$

As such, there has been a concerted effort to find a cheaper alternative to silicon solar cells. Recently, perovskite-based solar cells have been developed and have rapidly passed the efficiencies of many emerging and commercial photovoltaics, such as dye-sensitised, ${ }^{2}$ organic and amorphous silicon solar cells. $^{3}$ The term perovskite is given to all compounds which have the general chemical formula $\mathrm{ABX}_{3}$, and the crystal structure of calcium titanate $\left(\mathrm{CaTiO}_{3}\right)$. Organic-inorganic metal trihalide perovskites (where $\mathrm{A}$ is an organic cation, $\mathrm{B}$ a divalent metal ion, and $\mathrm{X}$ a halide or any mixture thereof) such as $\mathrm{CH}_{3} \mathrm{NH}_{3} \mathrm{PbX}{ }_{3}$, are promising alternatives to silicon, having both cheap and abundant starting materials, and being able to be manufactured by simple solution processing ${ }^{4-6}$ or scalable vapour phase deposition methods. ${ }^{7,} 8$ The first report of a solar cell incorporating a perovskite absorber was by Miyasaka and co-workers in 2009 and showed a 3.8\% efficient perovskite sensitised solar cell employing a liquid electrolyte. ${ }^{9}$ This efficiency was further increased to $6.5 \%$ by Park et al. in 2011. ${ }^{10}$ However, due to the corrosive nature of the liquid electrolyte, the perovskite material was dissolved within a few minutes of device operation. This prompted a shift towards solid-state hole conductors and within the last two years alone, the efficiencies of perovskite solar cells have leapt from around $10 \%$, 5, 11 to a certified $16.2 \%$ (NREL). ${ }^{12}$

One concern with this material is the toxicity of lead, and as such, a key scientific challenge is to replace the lead in the perovskite crystal with a less toxic metal, but no successes have yet been reported. The most viable replacements for $\mathrm{Pb}$ in the perovskite material are $\mathrm{Sn}$ and $\mathrm{Ge}$, also members of the group 14 metals. However, it is well known that the stability of the 2+ oxidation state decreases when moving up the group 14 elements, thus the major problem with the use of these metals is their chemical instability in the required oxidation state. Snbased perovskites in particular, have shown excellent mobilities in transistors, ${ }^{13}$ but can also be intentionally or unintentionally doped to become metallic. ${ }^{14,}{ }^{15}$ It has been demonstrated that when the $\mathrm{Sn}^{2+}$ ion is oxidised to $\mathrm{Sn}^{4+}$, the $\mathrm{Sn}^{4+}$ acts as a p-type dopant within the material in a process referred to as "selfdoping". ${ }^{14}$ To the best of our knowledge, there exists no previous report of a solar cell utilising a completely Pb-free, Sn-based perovskite as the absorber layer. A recent study by 
Ogimi et al. reported a mixed metal, $\mathrm{Sn}-\mathrm{Pb}$ perovskite which allowed tunability of the band gap of the perovskite absorber by varying the $\mathrm{Sn}: \mathrm{Pb}$ ratio, indicating that $\mathrm{Sn}$ could be a good choice of metal ion, especially for lower band gap solar cells. ${ }^{16}$ However, the same study reported that the neat $\mathrm{CH}_{3} \mathrm{NH}_{3} \mathrm{SnI}_{3}$ perovskite does not exhibit significant photovoltaic properties, and that a minimum content of $\mathrm{Pb}$ is needed to stabilize $\mathrm{Sn}$ in its $2+$ oxidation state.

Here we present materials and solar cell characterisation of photovoltaic devices employing the completely lead-free perovskite, methylammonium tin triiodide $\left(\mathrm{CH}_{3} \mathrm{NH}_{3} \mathrm{SnI}_{3}\right)$ as the photoactive material. Encapsulation of this material under inert atmosphere has allowed us to characterise the films and probe their performance in solar cells. We have obtained devices which yield power conversion efficiencies of greater than $6 \%$ under simulated full sunlight. We additionally derive the $\mathrm{THz}$ mobility and charge-carrier lifetime, which indicate that with reduction of the hole-doping density and further optimisation, this material should prove to be a viable, completely non-toxic alternative to $\mathrm{Pb}$-based perovskite solar cells, with the potential to deliver even higher efficiencies. Importantly, this demonstrates that Pb-based materials are not unique in delivering efficient perovskite solar cells.

\section{Results and discussion}

Due to the instability of $\mathrm{CH}_{3} \mathrm{NH}_{3} \mathrm{SnX} \mathrm{X}_{3}$ (where $\mathrm{X}=\mathrm{Cl}, \mathrm{Br}, \mathrm{I}$ ) in ambient atmosphere, we carried out all material and device processing in a nitrogen filled glovebox. We dissolved equimolar quantities of $\mathrm{SnI}_{2}$ and $\mathrm{CH}_{3} \mathrm{NH}_{3} \mathrm{I}$ in degassed $\mathrm{N}$ dimethylformamide (DMF), and then spin-coated the solution onto the desired substrates (fluorine doped tin oxide (FTO) coated in compact $\mathrm{TiO}_{2}$ and mesoporous $\mathrm{TiO}_{2}$ or $\mathrm{Al}_{2} \mathrm{O}_{3}{ }^{5}$, 17 for devices, $\mathrm{Al}_{2} \mathrm{O}_{3}$ or $\mathrm{TiO}_{2}$ coated glass for photoluminescence measurements, and $\mathrm{Al}_{2} \mathrm{O}_{3}$ or $\mathrm{TiO}_{2}$ coated z-cut quartz for terahertz spectroscopy samples) at 2000 rpm for 45 seconds. The dark brown, $\mathrm{CH}_{3} \mathrm{NH}_{3} \mathrm{SnI}_{3}$ perovskite (Figure S1) was formed on the substrate during spin-coating and required no further heating to crystallise. If after formation, the film was taken out into ambient atmosphere, we observed a decolouration of the film which occurred within seconds, suggesting a rapid degradation of the material. The instability of this material in ambient conditions is likely to be derived from the inherent instability of the $\mathrm{Sn}^{2+}$ ion in the presence of oxygen and moisture.

Under ambient conditions, the $\mathrm{Sn}^{2+}$ ion will rapidly oxidise to its more stable $\mathrm{Sn}^{4+}$ analogue. This process will destroy the charge neutrality of the perovskite structure and cause it to break down, resulting in the formation of oxides/hydroxides of Sn and methylammonium iodide (MAI). The diffraction pattern of an air-exposed sample of $\mathrm{CH}_{3} \mathrm{NH}_{3} \mathrm{SnI}_{3}$ is shown in the supplementary information (See Figure S2). In light of this, all measurements on this material were carried out on samples which were prepared and sealed under inert atmosphere. The exceptions to this were the samples prepared for scanning electron microscopy (SEM) and terahertz spectroscopy which remained unsealed, since the imaging and measurements were carried out under vacuum.

In order to investigate the structure and purity of the material, we performed X-ray diffraction (XRD) measurements. The diffraction pattern obtained (see Figure 1) is in good agreement with simulated and literature data, and corresponds to the tetragonal conformation of the perovskite structure. ${ }^{18}$ The structure is identical to that of the more widely used $\mathrm{CH}_{3} \mathrm{NH}_{3} \mathrm{PbX}_{3}$ perovskite, ${ }^{5,} 17$ showing that in this case, changing the central metal atom has not affected the overall crystal structure of the material. The lattice parameters derived from the X-Ray diffractogram were $\mathrm{a}=8.7912 \AA$ and $\mathrm{c}=$ $4.4770 \AA$.
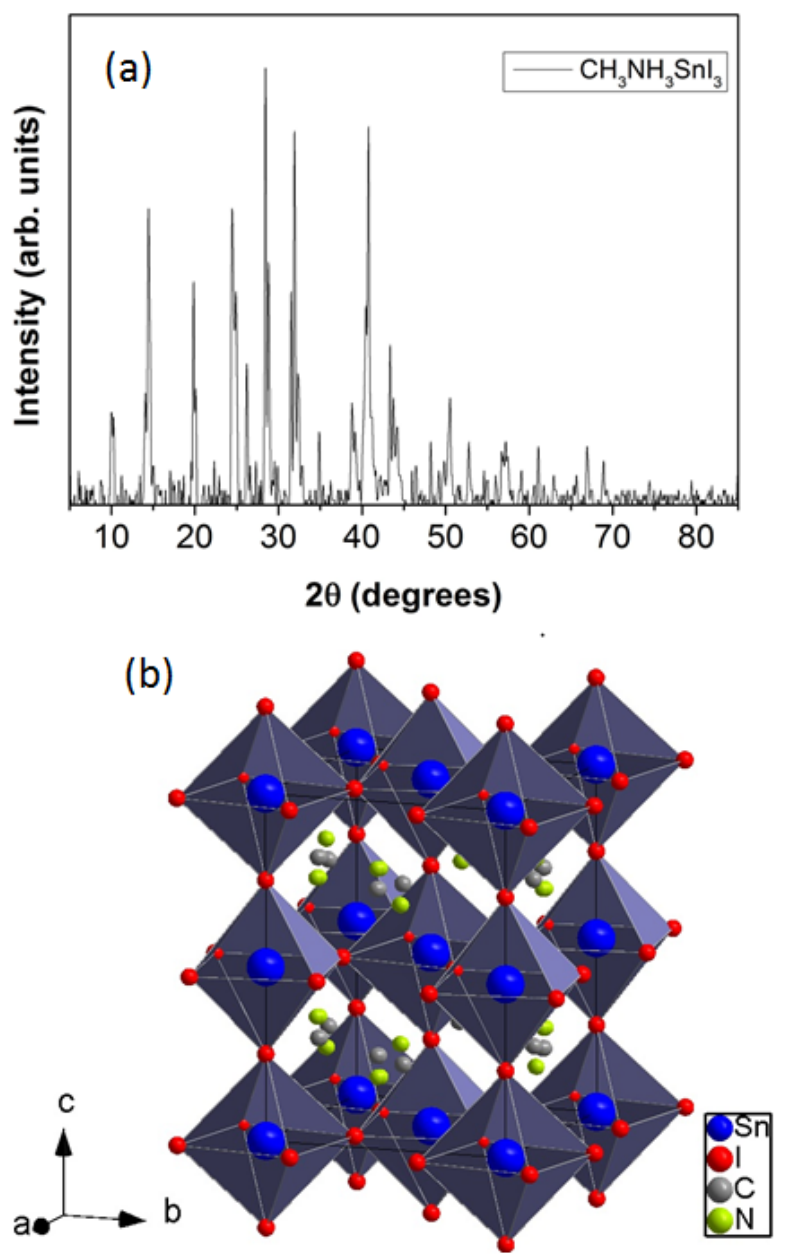

Figure 1: X-ray Diffraction (XRD) and Crystal Structure. (a) XRD pattern derived from a ground powder of $\mathrm{CH}_{3} \mathrm{NH}_{3} \mathrm{SnI}_{3}$. (b) Simulated crystal structure of $\mathrm{CH}_{3} \mathrm{NH}_{3} \mathrm{SnI}_{3}$ obtained from the diffraction pattern given in (a) showing the tetragonal conformation of the perovskite lattice.

The optical characterization of the material is shown in Figure 2a. The optical absorption characteristics of the material show a broad absorption edge at approximately $1000 \mathrm{~nm}$ and a broad photoluminescence peak at $980 \mathrm{~nm}$. In comparison, the lead perovskite, $\mathrm{CH}_{3} \mathrm{NH}_{3} \mathrm{PbI}_{3-\mathrm{x}} \mathrm{Cl}_{x}$, shows a sharper absorption edge at $770 \mathrm{~nm}$, and a narrower emission spectrum which has been recently shown to be homogeneously broadened. ${ }^{19}$ In order to provide a good estimation of the band gap of the $\mathrm{CH}_{3} \mathrm{NH}_{3} \mathrm{SnI}_{3}$ perovskite, we employed photo-thermal deflection spectroscopy (PDS). ${ }^{20}$ In Figure $\mathbf{2 b}$ we show the absorption profile extracted from the PDS measurements. The Tauc plot shown in the inset shows a sharp band edge at $1.23 \mathrm{eV}$. 

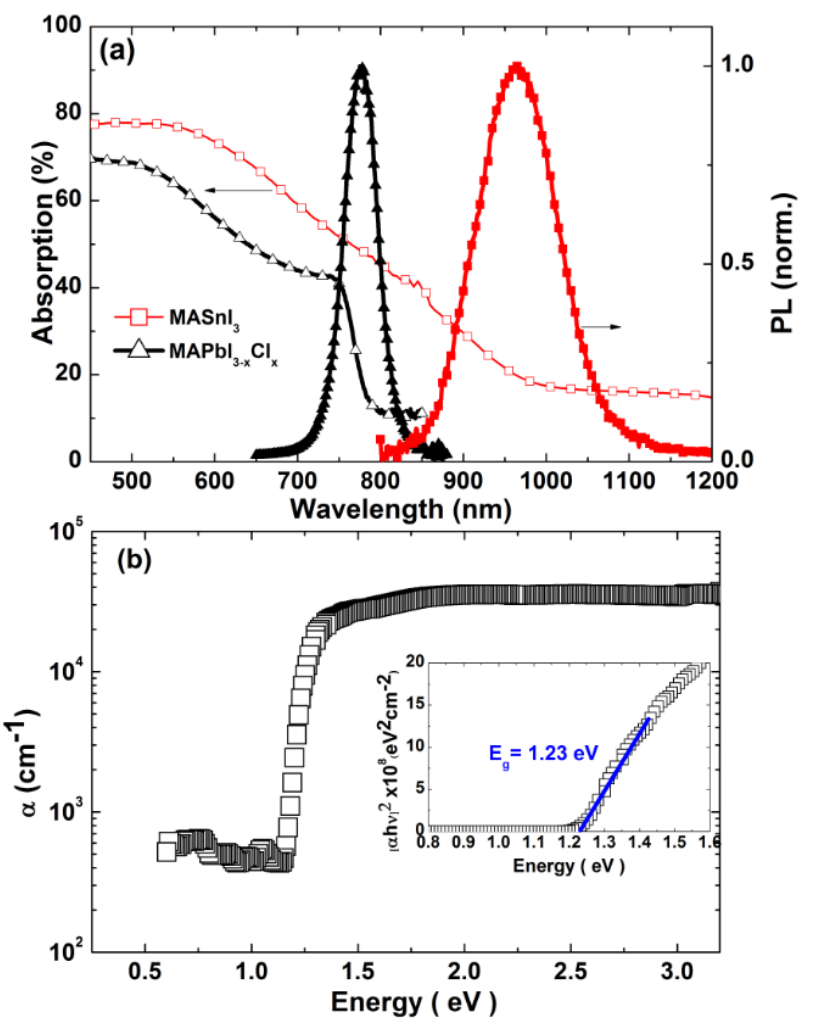

Figure 2: (a) Normalized steady state photoluminescence (PL) with photoexcitation at $500 \mathrm{~nm}$, and absorption taken with reflectance and transmission employing an integrating sphere of the tin-based and lead-based perovskites $\mathrm{CH}_{3} \mathrm{NH}_{3} \mathrm{SnI}_{3}$ and $\mathrm{CH}_{3} \mathrm{NH}_{3} \mathrm{PbI}_{3-\mathrm{x}} \mathrm{Cl}_{x}$ respectively. (b) The absorption profile of $\mathrm{CH}_{3} \mathrm{NH}_{3} \mathrm{SnI}_{3}$ as determined through photo-thermal deflection spectroscopy (PDS), with the band gap of the material determined using the Tauc plot (shown in inset). ${ }^{21}$ We note that since there may be strong exciton absorption at the band edge, the Tauc plot determined band gap can only be considered as an estimate.

Unlike the $\mathrm{Pb}$-based perovskite which requires heating to crystallise, the Sn perovskites crystallise at room temperature. This is actually an impediment to uniform film formation, as has previously been observed for $\mathrm{MAPbBr}_{3}$ which also crystallises directly upon spin-coating. ${ }^{9}, 22$ Directly upon spin coating, the $\mathrm{CH}_{3} \mathrm{NH}_{3} \mathrm{SnI}_{3}$ film crystallises, and in the case of a thin mesoporous $\mathrm{TiO}_{2}$ layer, large crystalline platelets can form on top of the surface in addition to the material which penetrates the pores. These crystalline platelets are apparent in the scanning electron microscopy (SEM) images shown in Figure 3a. This image displays a collection of large, 3-5 $\mu \mathrm{m}$, randomly oriented crystals in the case of the $\mathrm{CH}_{3} \mathrm{NH}_{3} \mathrm{SnI}_{3}$ perovskite films, whereas both planar heterojunction and mesosuperstructured $\mathrm{CH}_{3} \mathrm{NH}_{3} \mathrm{PbI}_{3-x} \mathrm{Cl}_{x}$ perovskite films have been shown to be much smoother with a greater degree of surface coverage (see Fig.3b). ${ }^{23,}{ }^{24}$ Previously, The $\mathrm{MAPbI}_{3-\mathrm{x}} \mathrm{Cl}_{\mathrm{x}}$ films also exhibited non-uniform coverage, and sporadic formation of islands on top of the mesoporous oxide films. ${ }^{25}$ However, with controlled crystallisation it has been possible to considerably improve the film formation. ${ }^{21,25,26}$ Conversely, in the case of a thicker mesoporous layer $(400 \mathrm{~nm})$ as is shown in Fig.3c, there is no visible capping layer of perovskite suggesting that all the crystallites are contained within the mesopores of the $\mathrm{TiO}_{2}$. A cross section of a complete device (which will be discussed later) is shown in Figure 3d. This device is fabricated with 400nm thick mesoporous $\mathrm{TiO}_{2}$ and in the cross section shown there does not appear to be a capping crystal. The dark region within the hole transporting material (HTM) phase is likely to be a shadowing effect rather than a perovskite capping layer. Additional SEM images are shown in the ESI.

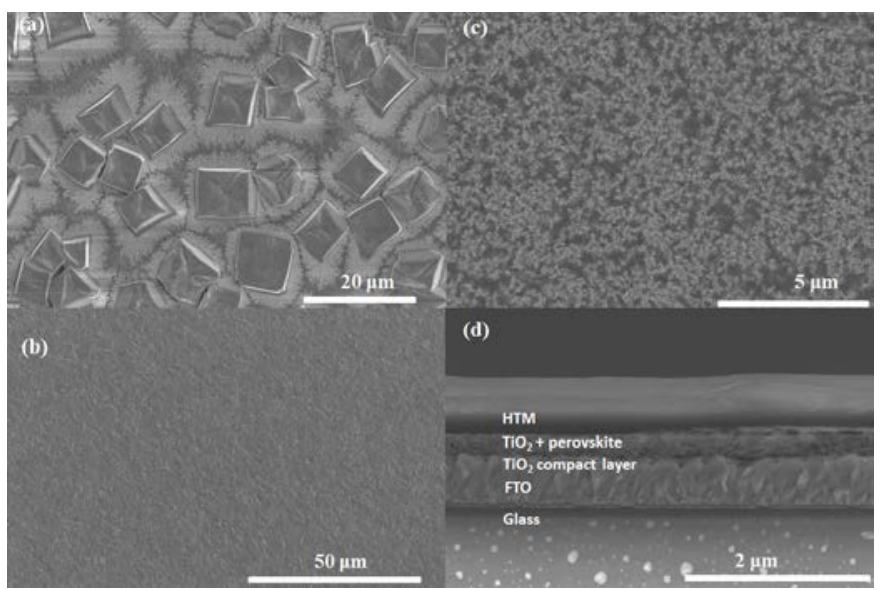

Figure 3: Scanning Electron Microscope (SEM) Images. (a) Top view of a film of $\mathrm{CH}_{3} \mathrm{NH}_{3} \mathrm{SnI}_{3}$ spin-coated onto mesoporous $\mathrm{TiO}_{2}$ (80nm thickness). (b) Top view of a film of $\mathrm{CH}_{3} \mathrm{NH}_{3} \mathrm{SnI}_{3}$ spin-coated onto mesoporous $\mathrm{TiO}_{2}(400 \mathrm{~nm}$ thickness). (c) Top view of a spin-coated film of $\mathrm{CH}_{3} \mathrm{NH}_{3} \mathrm{PbI}_{3-\mathrm{x}} \mathrm{Cl}_{\mathrm{x}}$ on mesoporous $\mathrm{TiO}_{2}$ (400 $\mathrm{nm}$ thickness). (d) Cross-sectional view of a complete device active layer composed of FTO glass/compact $\mathrm{TiO}_{2}(50 \mathrm{~nm}) /$ mesoporous $\mathrm{TiO}_{2}$ infiltrated with $\mathrm{CH}_{3} \mathrm{NH}_{3} \mathrm{SnI}_{3}(400 \mathrm{~nm}) / \mathrm{Spiro}-\mathrm{OMeTAD}$ (600nm).

One of the main reasons why the Pb-based perovskites perform so well in planar heterojunction and mesosuperstructured configurations is the sizeable diffusion length of the charge carriers. ${ }^{27,}{ }^{28}$ In the case of these materials, the PL lifetime has been determined to be a few hundred nanoseconds for $\mathrm{CH}_{3} \mathrm{NH}_{3} \mathrm{PbI}_{3-x} \mathrm{Cl}_{x}$ and at least 10 ns for the $\mathrm{CH}_{3} \mathrm{NH}_{3} \mathrm{PbI}_{3}$ perovskite. ${ }^{13,28}$ The presence of long-lived charge carriers allows these materials to operate efficiently in thin film architectures since the charges can be extracted from the device before significant recombination occurs, i.e., the diffusion length is much longer than the required thickness for complete light absorption. However, for $\mathrm{CH}_{3} \mathrm{NH}_{3} \mathrm{SnI}_{3}$, we found the PL decay lifetime to be similar to the instrument response of our Picoquant time correlated single photon counting set up in the infrared ( 200ps). Such a short PL lifetime may be due to fast recombination at either defect sites within the material, or to doped carriers resulting from the self-doping known to occur in the Sn perovskites. ${ }^{14,29}$

To probe the photophysical properties of $\mathrm{CH}_{3} \mathrm{NH}_{3} \mathrm{SnI}_{3}$ in more detail we performed time resolved optical pump $\mathrm{THz}$ probe spectroscopy, which provides a contactless probe for the conductivity of the material at picosecond time-resolution. A single-cycle $\mathrm{THz}$ pulse is incident on the sample at a welldefined time-delay, after being photoexcited by a 40 fs laser pulse at $550 \mathrm{~nm}$. By recording the photoinduced change of the transmitted $\mathrm{THz}$ amplitude, the transient conductivity of the thin-film sample can be reconstructed (see ESI for details). 
Knowing the photoexcitation density from the visible pulse, we can also extract an effective charge carrier mobility. ${ }^{30}$

In Figure 5a we display the transient photoinduced $\mathrm{THz}$ response of $\mathrm{CH}_{3} \mathrm{NH}_{3} \mathrm{SnI}_{3}$ over a range of excitation fluences between $11 \mu \mathrm{J} \mathrm{cm}^{-2}$ and $108 \mu \mathrm{J} \mathrm{cm}^{-2}$. We note that the corresponding $\mathrm{THz}$ spectra are consistent with a conductivity of free carriers in the presence of localization effects, such as those arising from backscattering at crystallite boundaries ${ }^{31}$ (see ESI for full details).
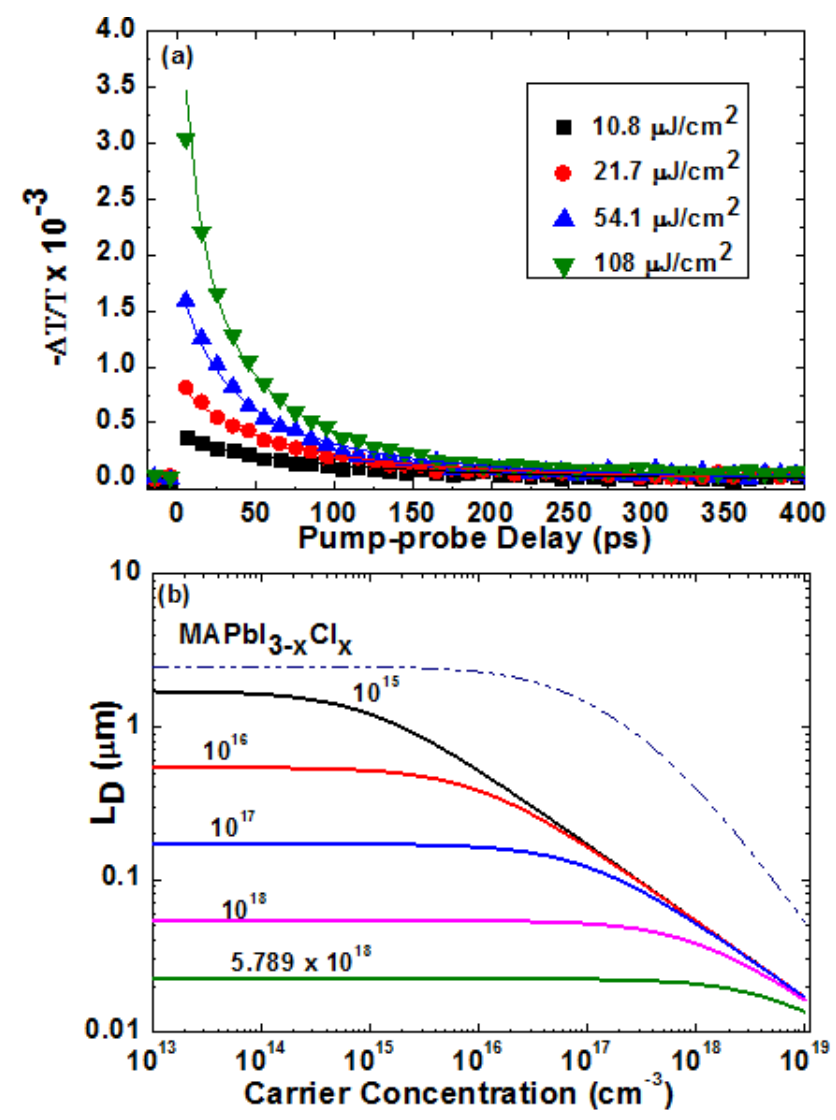

Figure 5: Terahertz (THz) Spectroscopy. (a) Transient terahertz photoconductivity of $\mathrm{CH}_{3} \mathrm{NH}_{3} \mathrm{SnI}_{3}$ on $80 \mathrm{~nm}$ thick $\mathrm{TiO}_{2}$ for a range of excitation fluences. Symbols represent experimental data while solid lines are fits to the data using the model described in the text. (b) Diffusion length ( $\mathrm{LD}_{\mathrm{D}}$ against the carrier concentration, $n$, for different hole doping levels as predicted from the model described in the text based on the rate constants extracted from fits to the data shown in (a) and neglecting trap-induced charge recombination. A decrease in the background level of doped holes corresponds to an increase in the diffusion length of the $\mathrm{CH}_{3} \mathrm{NH}_{3} \mathrm{SnI}_{3}$ perovskite. The dash-dotted line displays the diffusion length of the related, as prepared lead-based perovskite $\mathrm{CH}_{3} \mathrm{NH}_{3} \mathrm{PbI}_{3-\mathrm{x}} \mathrm{Cl}_{x}$ on mesoporous $\mathrm{Al}_{2} \mathrm{O}_{3}$ (from Ref. ${ }^{30}$ ) for comparison.

Previous Hall measurements on $\mathrm{CH}_{3} \mathrm{NH}_{3} \mathrm{SnI}_{3}$ have revealed about eight times higher mobilities, $\mu$, for electrons than for holes; therefore we expect that the transient $\mathrm{THz}$ response due to photoexcited carriers is dominated by free electrons. ${ }^{18} \mathrm{We}$ extract an effective free carrier mobility of $\varphi \mu=1.6 \mathrm{~cm}^{2} \mathrm{~V}^{-1} \mathrm{~s}^{-1}$, where $\varphi$ is the photon-to-free-charge conversion ratio, the precise value of which is unknown (see ESI). We note, however, that the likelihood of immediate generation of excitons as opposed to free carriers is small due to the high non-resonant excitation about $0.6 \mathrm{eV}$ above the band gap energy, such that $\varphi$ is likely to be close to unity.

Earlier conductivity studies on bulk $\mathrm{CH}_{3} \mathrm{NH}_{3} \mathrm{SnI}_{3}$ show strong levels of p-type self-doping due to the presence of $\mathrm{Sn}^{4+}$ impurities, on the order of $10^{16}-10^{18} \mathrm{~cm}^{-3} 14,29,32$. From our $\mathrm{THz}$ measurements we also observe a much faster monomolecular recombination rate than that which was observed with the Pb-based $\mathrm{CH}_{3} \mathrm{NH}_{3} \mathrm{PbI}_{3-\mathrm{x}} \mathrm{Cl}_{\mathrm{x}}$ perovskite. Therefore, assuming that the decay of the photoexcited electron population is predominantly governed by direct recombination with photoexcited and doped holes we obtain the rate equation

$$
\frac{\mathrm{d} n}{\mathrm{~d} t}=-\gamma n\left(p+p_{0}\right)=-\gamma n p-\gamma n p_{0}
$$

which we fitted simultaneously to the fluence-dependent $\mathrm{THz}$ conductivity transients (solid lines in Fig. 5a, full details in ESI). We note that the first term on the RHS of equation 1 represents bimolecular recombination between photogenerated carriers, while the second term describes a monomolecular recombination between photogenerated electrons with the fixed concentration, po, of dopant holes. We extract a value of $\varphi \gamma=1.4 \times 10^{-9} \mathrm{~cm}^{3} \mathrm{~s}^{-1}$ for the electron-hole bimolecular recombination rate constant, and a monomolecular decay constant of $\gamma p_{0}=8.08 \times 10^{9} \mathrm{~s}^{-1}$ from which we derive a holedoping density of $\varphi^{-1} p_{0}=5.8 \times 10^{18} \mathrm{~cm}^{3}$. Notably the value for $p_{o}$ is at the higher end of that reported in previous studies, consistent with a significant extent of self-doping. ${ }^{29}$

With the knowledge of the charge-carrier mobility and the recombination rates, we are able to derive a charge-diffusion length of $30 \mathrm{~nm}$ under realistic device operating conditions (see ESI for details). This value falls substantially short of the diffusion length of over 1 micron reported for $\mathrm{CH}_{3} \mathrm{NH}_{3} \mathrm{PbI}_{3}$ ${ }_{x} \mathrm{Cl}_{x},{ }^{27}, 30$ suggesting that the $\mathrm{Sn}$-based material, as prepared here, is unlikely to function well as a solar cell absorber in a planar heterojunction architecture, and should hence require a distributed heterojunction. These measurements were taken for $\mathrm{CH}_{3} \mathrm{NH}_{3} \mathrm{SnI}_{3}$ coated on $80 \mathrm{~nm}$ thick films of mesoporous $\mathrm{TiO}_{2}$, similar values were obtained for $\mathrm{CH}_{3} \mathrm{NH}_{3} \mathrm{SnI}_{3}$ coated upon $80 \mathrm{~nm}$ thick films of mesoporous $\mathrm{Al}_{2} \mathrm{O}_{3}$ (See ESI, Figure S5).

Since we know the effective mobility, the bimolecular recombination rate constant, and have an estimate of the background concentration of doped holes, we can extrapolate how the diffusion length would change if the background concentration of doped holes were to be decreased (see ESI for details). In Fig.5b, we show a graph of simulated diffusion length against photoexcited carrier concentration for five different doped hole concentrations. For comparison a plot of the actual diffusion length of the as prepared $\mathrm{Pb}$ analogue $\left(\mathrm{CH}_{3} \mathrm{NH}_{3} \mathrm{PbI}_{3-\mathrm{x}} \mathrm{Cl}_{\mathrm{x}}\right)$ is added. We show here that if the background doping level in the $\mathrm{CH}_{3} \mathrm{NH}_{3} \mathrm{SnI}_{3}$ perovskite were to be decreased to the order of $10^{15} \mathrm{~cm}^{-3}$, then the diffusion length could increase beyond a micron in length and approach that of the very efficient $\mathrm{Pb}$-based perovskite system. This result is a direct consequence of the low bi-molecular recombination rate observed for the material, which is similarly low compared to the value previously determined for the Pb-based counterpart.

Despite the slightly lower $\mathrm{THz}$ carrier mobility, this rate is still short of the prediction of the Langevin model by a factor $5 \times 10^{4} \times \epsilon^{-1}$, with $\epsilon$ being the relative permittivity of the material. Our observations clearly identify a reduction of self-doping as a promising strategy to enhance the carrier 
lifetime and hence, prospects for efficient photovoltaic operation. With the knowledge of the short diffusion length, we fabricated perovskite-sensitised solar cells (PSSCs), composed of FTO coated glass/ compact $\mathrm{TiO}_{2} /$ mesoporous $\mathrm{TiO}_{2}$ (400nm) coated with the $\mathrm{CH}_{3} \mathrm{NH}_{3} \mathrm{SnI}_{3} /$ Spiro$\mathrm{OMeTAD} / \mathrm{Au}$. The entire device was assembled in a nitrogen-filled glovebox after which the devices were transferred to the evaporator located within the glovebox, hence avoiding exposure to air. Encapsulation was subsequently performed under the same conditions using a hot melt polymer laminate with a glass coverslip, and epoxy resin to seal around the edges. This was done so that the device was exposed to negligible levels of oxygen or moisture during fabrication. The sealed cells were then removed from the glove box and immediately measured in air. Control devices using the Pb-based perovskite as an absorber were also fabricated in the glovebox and tested in the same manner, but without encapsulation. Device performance parameters from a batch of cells, along with the current-voltage characteristics of the best devices, are presented in Figure 4. Current-voltage characteristics for devices with varying performance are shown in the ESI.
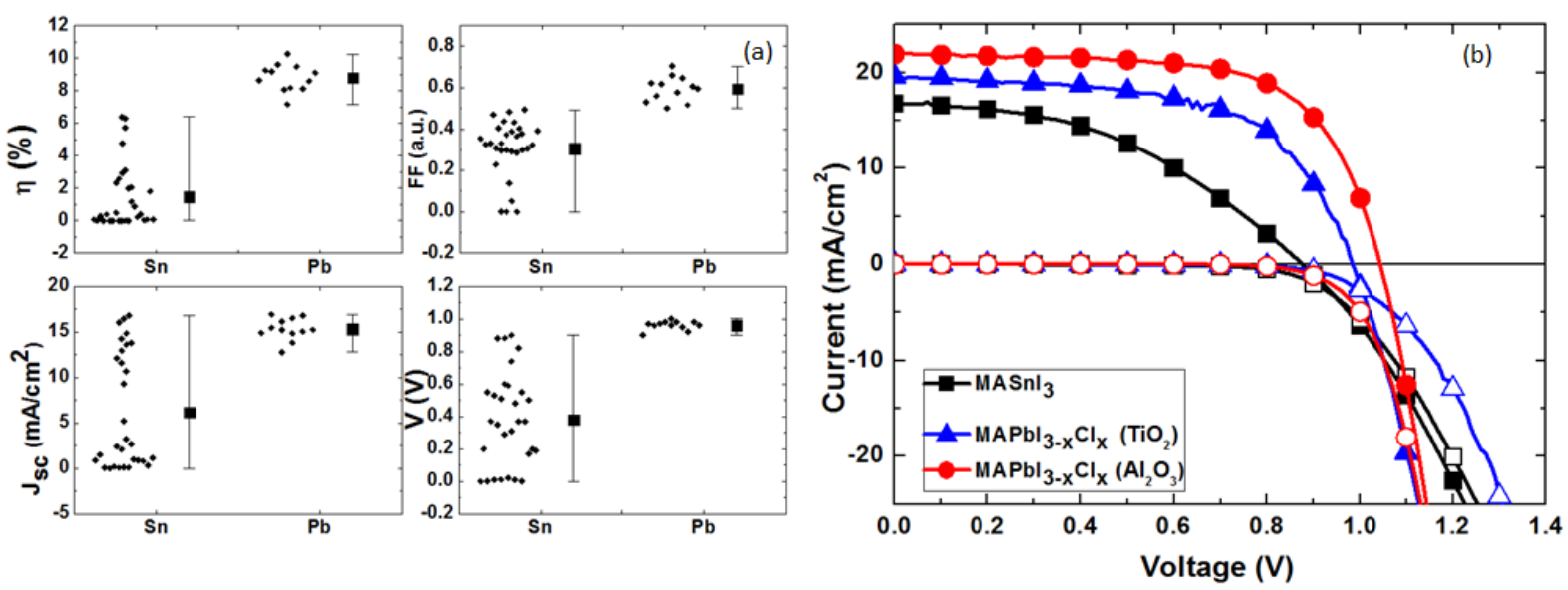

Figure 4: Current-Voltage Characteristics and Device Performance Parameters. (a) The solar cell performance parameters extracted from measuring current-voltage curves under AM1.5 simulated sun light of $100 \mathrm{mWcm}^{-2}$ for $\mathrm{TiO}_{2}-\mathrm{based}$ perovskite sensitized solar cells employing $\mathrm{CH}_{3} \mathrm{NH}_{3} \mathrm{SnI}_{3}(\mathrm{Sn})$ and $\mathrm{CH}_{3} \mathrm{NH}_{3} \mathrm{PbI}_{3-\mathrm{x}} \mathrm{Cl} \mathrm{I}_{\mathrm{x}}(\mathrm{Pb}$ ) absorbers. (b) Current-voltages curves of the best Sn-based and Pb-based devices for the batch of devices shown in (a). Light JV curves are denoted with

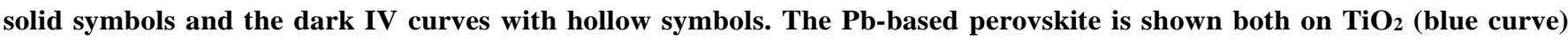
and $\mathrm{Al}_{2} \mathrm{O}_{3}$ (red curve) giving short circuit currents $\left(\mathrm{J}_{\mathrm{sc}}\right)$ of $19.6 \mathrm{mAcm}{ }^{-2}$ and $21.9 \mathrm{mAcm}^{-2}$, open circuit voltages $\left(\mathrm{V}_{\mathrm{oc}}\right)$ of 0.98 $\mathrm{V}$ and $1.04 \mathrm{~V}$, fill factors (FF) of 0.60 and 0.66 , and power conversion efficiencies ( $\eta$ ) of $11.5 \%$ and $15.0 \%$ respectively. While the Sn-based perovskite showed negligible photovoltaic properties on $\mathrm{Al}_{2} \mathrm{O}_{3}$, on $\mathrm{TiO}_{2}$ a maximum $\eta$ of $6.4 \%$ was obtained, corresponding to a $\mathrm{V}_{\mathrm{oc}}$ of $0.88 \mathrm{~V}, \mathrm{~J}_{\mathrm{sc}}$ of $16.8 \mathrm{mAcm}^{-2}$ and FF of 0.42 . It is important to note that the Sn-based devices were fabricated, metal electrodes evaporated and devices sealed in a nitrogen filled glove box prior to exposing to air.

There is a broad spread in the performance of the $\mathrm{CH}_{3} \mathrm{NH}_{3} \mathrm{SnI}_{3}$ solar cells. Here we show that the best performing Sn-based device reaches a power efficiency of 6.4\% under 1sun illumination. Quite remarkably, for an absorber with a bandgap of $1.23 \mathrm{eV}$, the open circuit voltages reach values as high $0.88 \mathrm{~V}$ in the most efficient device. The fundamental energy loss in a photovoltaic system can be taken as the difference between the bandgap and the open-circuit voltage obtained. ${ }^{33}$ For crystalline silicon solar cells, which currently dominate the market, this loss is approximately $0.35 \mathrm{eV}$, while for GaAs, our closest example of a perfectly ordered crystalline material, the loss is in the range of $0.27 \mathrm{eV} .3,34,35$ Here, the loss we estimate is only $0.35 \mathrm{eV}$ in the best performing cells, which matches that of $\mathrm{C}-\mathrm{Si}^{36}$

Observing such high open-circuit voltages in these solar cells is unexpected considering the relatively short lifetime and hence diffusion length, as well as the use of mesoporous $\mathrm{TiO}_{2}$, which has previously resulted in lower open-circuit voltages in $\mathrm{CH}_{3} \mathrm{NH}_{3} \mathrm{PbI}_{3-\mathrm{x}} \mathrm{Cl}_{\mathrm{x}}$ solar cells. ${ }^{5,}{ }^{37}$ However, if the low diffusion length is a consequence of the fast recombination to doped carriers as we infer, then this will not necessarily impede the open-circuit voltage. The inferred high p-doping density $\left(10^{18} \mathrm{~cm}^{-3}\right)$ is much higher than the photo-induced charge density under full sun light $\left(<10^{15} \mathrm{~cm}^{-3}\right.$ for the Pb-based perovskite). ${ }^{27,} 38$ This implies that under open-circuit conditions where no holes can be swept out of the device, the quasi Fermi level for holes will be very close to the valence band edge. Provided that electrons can transfer quickly and efficiently to the $\mathrm{TiO}_{2}$, in principle the quasi Fermi level for electrons may be set by the Fermi level in the $\mathrm{TiO}_{2}$. The additional surprise is that the mesoporous $\mathrm{TiO}_{2}$ would also have to become comparably doped to enable the quasi Fermi level for electrons to be close to the conduction band, which is required to sustain such a high open-circuit voltage under illumination. 
In Figure S4 we show a zoom-in of the dark currentvoltage curves, and we note that the dark current for the best device only exhibits marginally more leakage at low bias (0 to $0.6 \mathrm{~V}$ ) than the $\mathrm{Pb}$ based perovskite solar cells. However, for the poorer performing cells the dark current leakage is significant, as we show in Figure S5, and is largely responsible for the wide spread in open-circuit voltage. It is likely that there is a range of doping densities within the as prepared and tested devices which could account for this variable dark current leakage. Evidently, this does require further investigation. While one would expect higher short-circuit currents from a low band gap system such as this, a major factor which would inhibit both the $\mathrm{J}_{\mathrm{sc}}$ and the FF is the short electron diffusion length. We have identified that this is likely to be due to excessive self-doping, but with appropriate control of this phenomenon, coupled with improved control of the thin film processing, these early solar cell results are very promising. We must note however, that even with encapsulation the devices still quickly degrade when tested under ambient conditions. Within minutes of measuring, a deeply coloured device can become completely transparent. X-ray diffraction measurements of the degraded solar cells, which we show in SI, indicate complete degradation of the perovskite structure. This is indicative of either our current device sealing protocol failing to prevent oxygen/ moisture from causing device degradation or a fundamental instability of the material.

In the devices, we employ metal electrodes to extract the current, and it is not possible with our current configuration to completely seal beneath the electrodes. Hence oxygen and moisture could ingress the film through the active layer beneath the electrodes. In order to determine if complete sealing would inhibit the rapid degradation, we processed $\mathrm{CH}_{3} \mathrm{NH}_{3} \mathrm{SnI}_{3}$ films on large glass substrates and scraped all the material away from the edge of the glass slides. We then completely sealed the slides with the hot-melt polymer film, a glass cover slide and edge sealed with epoxy resin. These films were subject to a continuous light soaking over a 4-month period. After 4 months the films were still visibly coloured, as we show in Figure S1, and there was no significant drop in their absorbance indicating that with appropriate current extraction and sealing protocol, predominant stabilisation should be possible.

\section{Conclusions}

In summary, we have provided the first demonstration of an efficient, completely lead-free perovskite solar cell using the Sn-based perovskite, $\mathrm{CH}_{3} \mathrm{NH}_{3} \mathrm{SnI}_{3}$ as the absorber layer. This shows that good photovoltaic performance and unexpectedly high open-circuit voltage is not strictly limited to lead-based perovskites. These devices yielded efficiencies of more than $6 \%$, however the stability of $\mathrm{CH}_{3} \mathrm{NH}_{3} \mathrm{SnI}_{3}$ remains a challenge.
The voltage losses in the material appear to be remarkably low, suggesting that when its full potential is exploited, the efficiencies could very well approach those of c-Si and GaAs. We have determined the mobility of the as prepared films to be approximately $1.6 \mathrm{~cm}^{2} \mathrm{~V}^{-1} \mathrm{~s}^{-1}$ and the diffusion length to be approximately $30 \mathrm{~nm}$ as compared to over a micron in the $\mathrm{Pb}$ based perovskites, $\mathrm{CH}_{3} \mathrm{NH}_{3} \mathrm{PbX}_{3}{ }^{27}, 28,30$ However, the diffusion length is limited by recombination with self-doping carriers, and if the background concentration of holes were to be decreased, then the diffusion length could approach 1 micron, opening the possibility for planar heterojunction devices. The pivotal issue is now the stabilisation of the material such that the oxidation of the Sn within the crystal is supressed, thus reducing the doping levels of the material and enabling long term stable operation. By achieving a solution to this, we may see the performance of Sn perovskites surpassing those of the state-of-the-art Pb-based perovskites over the next few years, with a distinct toxicology advantage.

\section{Experimental}

\section{Device Fabrication}

Briefly, FTO-coated glass sheets (7_ $\mathrm{cm}^{-1}$ Pilkington) were etched with zinc powder and $\mathrm{HCl}(3 \mathrm{M})$ to obtain the required electrode pattern. The sheets were then washed with soap (2\% Hellmanex in water), deionized water, acetone, and methanol, and finally treated under oxygen plasma for $10 \mathrm{~min}$ to remove the last traces of organic residues. All chemicals were purchased from Sigma Aldrich and used as received unless otherwise stated. A $100 \mathrm{~nm}$ thick compact layer of $\mathrm{TiO}_{2}$ was then deposited on the glass using titanium isopropoxide (99.999\% purity) diluted in anhydrous ethanol and sintered for 45 mins at $500^{\circ} \mathrm{C}$. After the substrate was allowed to cool, a $400 \mathrm{~nm}$ thick layer of $\mathrm{TiO}_{2}$ (Dyesol $18 \mathrm{NRT}$ ) was deposited via spin coating at $2000 \mathrm{rpm}$ for $1 \mathrm{~min}$. The substrate was then resintered at $500^{\circ} \mathrm{C}$ for $45 \mathrm{~min}$.

The $\mathrm{CH}_{3} \mathrm{NH}_{3} \mathrm{SnI}_{3}$ perovskite precursor solution was prepared by dissolving equimolar quantities of $\mathrm{CH}_{3} \mathrm{NH}_{3} \mathrm{I}$ and $\mathrm{SnI}_{2}$ to a concentration of $40 \mathrm{wt} \%$ in $\mathrm{N}$-dimethylformamide (DMF). The precursor solution was then spin coated onto the $\mathrm{TiO}_{2}$ coated substrate under inert atmosphere. The perovskite layer formed during spin coating. After formation of the perovskite layer, the hole transporting material (HTM) 2,2',7,7'-tetrakis(N,N'-di-pmethoxyphenylamine)-9,9'-spirobifluorene (spiro-OMeTAD) was dissolved in (concentration $80 \mathrm{mM}$ ) with addition of additives at a concentration of $10 \mathrm{mM}$ hydrogen bis(trifluoromethanesulfonyl)imide (H-TFSI) and $80 \mathrm{mM}$ tertbutylpyridine (tBP). ${ }^{39}$ We note that the additives combination commonly used with spiro-OMeTAD, $15 \mathrm{mM}$ of lithium bis(trifluoromethylsulfonyl)imide salt (Li-TFSI) and $70 \mathrm{mM}$ of 4-tert-butylpyridine (tBP), made the $\mathrm{CH}_{3} \mathrm{NH}_{3} \mathrm{SnI}_{3}$ more unstable than H-TFSI. Lastly, $50 \mathrm{~nm}$ thick gold electrodes 
were evaporated onto the devices through a shadow mask, using a thermal evaporator giving an effective active area of $0.12 \mathrm{~cm}^{-2}$ as defined by the overlap of the gold and FTO electrodes. The devices were then sealed under inert atmosphere, using a meltable polymer and an epoxy resin.

\section{Solar Cell Characterization}

Solar cell performance was measured using a class AAB ABET solar simulator which was calibrated to give simulated AM 1.5 sunlight at an irradiance of $100 \mathrm{~mW} / \mathrm{cm}^{2}$. The irradiance was calibrated using an NREL-calibrated KG5 filtered silicon reference cell. Current-Voltage curves were recorded using a sourcemeter (Keithley 2400, USA). All solar cells were masked with a metal aperture which was used to define the active area of the devices, which in this case was $0.0625 \mathrm{~cm}^{2}$.

\section{Optical Characterization}

Samples for optical characterisation were prepared using a similar precursor solution as for the devices. A 1:2 dilution of $\mathrm{Al}_{2} \mathrm{O}_{3}$ nanoparticles in isopropanol was spin coated onto a glass slide, resulting in a layer which was $80 \mathrm{~nm}$ thick. The Snperovskite precursor solution was then spin coated onto the substrate at $2000 \mathrm{rpm}$, under inert atmosphere. After the formation of the perovskite, the slides were sealed in the same manner as the devices. The steady-state absorption spectra were acquired with a Perkin-Elmer Lambda 1050 UV/Vis/NIR spectrophotometer using an integrating sphere to account for reflection and scattering. We note however that the films were located on the front and back of the integrating sphere for the transmission and reflection measurements and severe scattering out of the sides of the substrates escapes the integrating sphere and will hence erroneously appear as an absorption.

Steady-state photoluminescence (PL) measurements were taken using an automated spectrofluorometer (Fluorolog, Horiba Jobin-Yvon), with a $450 \mathrm{~W}$ Xenon lamp excitation source and liquid nitrogen cooled InGaAs NIR detector for $\mathrm{CH}_{3} \mathrm{NH}_{3} \mathrm{SnI}_{3}$ samples and a photomultiplier tube detector for $\mathrm{CH}_{3} \mathrm{NH}_{3} \mathrm{PbI}_{3}$ ${ }_{\mathrm{x}} \mathrm{Cl}_{\mathrm{x}}$ samples. The excitation wavelength was $500 \mathrm{~nm}$. All spectra were corrected for instrumental response using a calibration lamp of known emissivity.

\section{Photothermal Deflection Spectroscopy}

Photothermal Deflection Spectroscopy (PDS) is a highly sensitive surface averaged absorption measurement technique. Full details about this experiment are described elsewhere. ${ }^{40}$ For this measurement $300 \mathrm{~nm}$ thick $\mathrm{CH}_{3} \mathrm{NH}_{3} \mathrm{SnI}_{3}$ perovskite layers were spin coated onto quartz substrates from the precursor solution.

\section{THz Time Domain Spectroscopy}

Full experimental detail is given elsewhere. The optical-pumpTHz-probe setup uses a Ti:Sapphire regenerative amplifier to generate $40 \mathrm{fs}$ pulses at $800 \mathrm{~nm}$ wavelength and a repetition rate

of $1.1 \mathrm{kHz}$. Terahertz pulses are generated by optical rectification in $450 \mu \mathrm{m}$ thick (110)-GaP and detected by electro-optic sampling in a ZnTe crystal (0.2 mm (110)-ZnTe on $3 \mathrm{~mm}$ (100)-ZnTe). Pulses for optical excitation of the samples at a wavelength of $550 \mathrm{~nm}$ have been generated using an optical parametric amplifier (OPA). Optical excitation was carried out from the non-substrate side of the film. The diameters of pump and probe beam at the sample position are $4.2 \mathrm{~mm}$ and $1.5 \mathrm{~mm}$ (FWHM). Measurements have been performed with the entire $\mathrm{THz}$ beam path (including emitter, detector and sample) in an evacuated chamber at pressure of < $10^{-1}$ mbar.

\section{Acknowledgements}

This work was supported by EPSRC and the European Research Council (ERC) HYPER PROJECT no. 27988. N.N. thanks the Government of the Republic of Trinidad and Tobago for additional financial support. The authors would like to thank Dr. James M. Ball for device photography and helpful discussions; Dr. Martina Congiu for SEM images; and Sir Professor Richard Friend and Severin N. Habisreutinger for helpful discussions.

\section{Notes and references}

${ }^{a}$ Clarendon Laboratory, Department of Physics, University of Oxford, Parks Road, Oxford, OX1 3PU, United Kingdom

$b$ Italian Institute of Technology, Centre for Nano Science and Technology, Politecnico di Milano, Via Pascoli 70/3,20133 Milan, Italy

c Dipartimento di Fisica, Politecnico di Milano, Piazza L. da Vinci 32, 20133 Milano, Italy.

$d$ Cavendish Laboratory, Department of Physics, University of Cambridge, 19 JJ Thomson Ave, Cambridge, CB3 0HE, United Kingdom Electronic Supplementary Information (ESI) available: Additional experimental detail, XRD and photographs of degraded $\mathrm{CH}_{3} \mathrm{NH}_{3} \mathrm{SnI}_{3}$, additional cross-sectional and top view images, terahertz absorption and conductivity on $80 \mathrm{~nm} \mathrm{Al} \mathrm{O}_{3}$ as well as details of the terahertz modelling are all available. See DOI: 10.1039/b000000x/

1.
C. Steven and M. Arun, Nature, 2012, 488, 294-303.

A. Yella, H.-W. Lee, H. N. Tsao, C. Yi, A. K. Chandiran, M. K. Nazeeruddin, E. W.-G. Diau, C.-Y. Yeh, S. M. Zakeeruddin and M. Grätzel, Science, 2011, 334, 629-634.

M. A. Green, K. Emery, Y. Hishikawa, W. Warta and E. D. Dunlop, Progress in Photovoltaics: Research and Applications, 2014, 22, 1-9.

J. A. Chang, S. H. Im, Y. H. Lee, H.-j. Kim, C.-S. Lim, J. H. Heo and S. I. Seok, Nano Letters, 2012, 12, 1863-1867.

M. M. Lee, J. Teuscher, T. Miyasaka, T. N. Murakami and H. J. Snaith, Science, 2012, 338, 643-647.

J. Burschka, N. Pellet, S.-J. Moon, R. Humphry-Baker, P. Gao, M. K. Nazeeruddin and M. Gratzel, Nature, 2013, 499, 316-319.

M. Liu, M. B. Johnston and H. J. Snaith, Nature, 2013, 501, 395398.

O. Malinkiewicz, A. Yella, Y. H. Lee, G. M. Espallargas, M. Graetzel, M. K. Nazeeruddin and H. J. Bolink, Nat Photon, 2014,

$\mathbf{8}, 128-132$. American Chemical Society, 2009, 131, 6050-6051.

J.-H. Im, C.-R. Lee, J.-W. Lee, S.-W. Park and N.-G. Park, Nanoscale, 2011, 3, 4088-4093. 
11. J. H. Noh, S. H. Im, J. H. Heo, T. N. Mandal and S. I. Seok, Nano Letters, 2013, 13, 1764-1769.

12. N. R. E. L. (NREL), NREL, www.nrel.gov/ncpv/images/efficiency_chart.jpg.

13. C. R. Kagan, D. B. Mitzi and C. D. Dimitrakopoulos, Science, 1999, 286, 945-947.

14. Y. Takahashi, R. Obara, Z.-Z. Lin, Y. Takahashi, T. Naito, T. Inabe, S. Ishibashi and K. Terakura, Dalton Transactions, 2011, 40, 5563-5568.

$15 . \quad$ D. B. Mitzi, C. A. Feild, Z. Schlesinger and R. B. Laibowitz, Journal of Solid State Chemistry, 1995, 114, 159-163.

16. Y. Ogomi, A. Morita, S. Tsukamoto, T. Saitho, N. Fujikawa, Q. Shen, T. Toyoda, K. Yoshino, S. S. Pandey, T. Ma and S. Hayase, The Journal of Physical Chemistry Letters, 2014, 1004-1011.

17. J. M. Ball, M. M. Lee, A. Hey and H. Snaith, Energy \& Environmental Science, 2013.

$18 . \quad$ C. C. Stoumpos, C. D. Malliakas and M. G. Kanatzidis, Inorganic Chemistry, 2013, 52, 9019-9038.

19. C. Wehrenfennig, M. Liu, H. J. Snaith, M. B. Johnston and L. M. Herz, The Journal of Physical Chemistry Letters, 2014, 13001306.

$20 . \quad$ S. De Wolf, J. Holovsky, S.-J. Moon, P. Löper, B. Niesen, M. Ledinsky, F.-J. Haug, J.-H. Yum and C. Ballif, The Journal of Physical Chemistry Letters, 2014, 5, 1035-1039.

21. G. E. Eperon, S. D. Stranks, C. Menelaou, M. B. Johnston, L. M. Herz and H. J. Snaith, Energy \& Environmental Science, 2014, 7, 982-988.

22. E. Edri, S. Kirmayer, D. Cahen and G. Hodes, The Journal of Physical Chemistry Letters, 2013, 4, 897-902.

23. K. W. Tan, D. T. Moore, M. Saliba, H. Sai, L. A. Estroff, T. Hanrath, H. J. Snaith and U. Wiesner, ACS Nano, 2014.

$24 . \quad$ M. Saliba, K. W. Tan, H. Sai, D. T. Moore, T. Scott, W. Zhang, L. A. Estroff, U. Wiesner and H. J. Snaith, The Journal of Physical Chemistry C, 2014.

$25 . \quad$ G. E. Eperon, V. M. Burlakov, P. Docampo, A. Goriely and H. J. Snaith, Advanced Functional Materials, 2014, 24, 151-157.

$26 . \quad$ B. Conings, L. Baeten, C. De Dobbelaere, J. D'Haen, J. Manca and H.-G. Boyen, Advanced Materials, 2014, 26, 2041-2046.

$27 . \quad$ S. D. Stranks, G. E. Eperon, G. Grancini, C. Menelaou, M. J. P. Alcocer, T. Leijtens, L. M. Herz, A. Petrozza and H. J. Snaith, Science, 2013, 342, 341-344.

$28 . \quad$ G. Xing, N. Mathews, S. Sun, S. S. Lim, Y. M. Lam, M. Grätzel, S. Mhaisalkar and T. C. Sum, Science, 2013, 342, 344-347.

29. Y. Takahashi, H. Hasegawa, Y. Takahashi and T. Inabe, J. Solid State Chem., 2013, 205, 39-43.

30. C. Wehrenfennig, G. E. Eperon, M. B. Johnston, H. J. Snaith and L. M. Herz, Advanced Materials, 2014, 26, 1584-1589.

31. H. Němec, P. Kužel and V. Sundström, Phys. Rev. B, 2009, 79, 115309.

32. D. B. Mitzi, C. A. Feild, Z. Schlesinger and R. B. Laibowitz, J. Solid State Chem., 1995, 114, 159-163.

33. H. J. Snaith, Advanced Functional Materials, 2010, 20, 13-19.

34. P. K. Nayak, J. Bisquert and D. Cahen, Advanced Materials, 2011, 23, 2870-2876.

$35 . \quad$ P. K. Nayak and D. Cahen, Advanced Materials, 2014, 26, 16221628.

36. W. Shockley and H. J. Queisser, Journal of Applied Physics, 1961, 32, 510-519.

37. T. Leijtens, B. Lauber, G. E. Eperon, S. D. Stranks and H. J. Snaith, The Journal of Physical Chemistry Letters, 2014, 5, 10961102.

38. V. D’Innocenzo, G. Grancini, M. J. P. Alcocer, A. R. S. Kandada, S. D. Stranks, M. M. Lee, G. Lanzani, H. J. Snaith and A. Petrozza, Nat Commun, 2014, 5.

39. A. Abate, D. J. Hollman, J. Teuscher, S. Pathak, R. Avolio, G. D'Errico, G. Vitiello, S. Fantacci and H. J. Snaith, Journal of the American Chemical Society, 2013, 135, 13538-13548.

$40 . \quad$ A. J. Kronemeijer, V. Pecunia, D. Venkateshvaran, M. Nikolka, A. Sadhanala, J. Moriarty, M. Szumilo and H. Sirringhaus, Advanced Materials, 2014, 26, 728-733. 